\title{
Mass incarceration and public health: the association between black jail incarceration and adverse birth outcomes among black women in Louisiana
}

\author{
Lauren Dyer $^{1^{*}} \mathbb{D}$, Rachel Hardeman ${ }^{2}$, Dovile Vilda ${ }^{1}$, Katherine Theall ${ }^{1}$ and Maeve Wallace ${ }^{1}$
}

\begin{abstract}
Background: A growing body of evidence is beginning to highlight how mass incarceration shapes inequalities in population health. Non-Hispanic blacks are disproportionately affected by incarceration and criminal law enforcement, an enduring legacy of a racially-biased criminal justice system with broad health implications for black families and communities. Louisiana has consistently maintained one of the highest rates of black incarceration in the nation. Concurrently, large racial disparities in population health persist.

Methods: We conducted a cross-sectional analysis of all births among non-Hispanic black women in Louisiana in 2014 to identify associations between parish-level (county equivalent) prevalence of jail incarceration within the black population and adverse birth outcomes $(N=23,954)$. We fit a log-Poisson model with generalized estimating equations to approximate the relative risk of preterm birth and low birth weight associated with an interquartile range increase in incarceration, controlling for confounders. In sensitivity analyses, we additionally adjusted for the parish-level index crime prevalence and analyzed regression models wherein white incarceration was used to predict the risk of adverse birth outcomes in order to quantify the degree to which mass incarceration may harm health above and beyond living in a high crime area.

Results: There was a significant 3\% higher risk of preterm birth among black women associated with an interquartile range increase in the parish-level incarceration prevalence of black individuals, independent of other factors. Adjusting for the prevalence of index crimes did not substantively change the results of the models.

Conclusion: Due to the positive significant associations between the prevalence of black individuals incarcerated in Louisiana jails and estimated risk of preterm birth, mass incarceration may be an underlying cause of the persistent inequities in reproductive health outcomes experienced by black women in Louisiana. Not only are there economic and social impacts stemming from mass incarceration, but there may also be implications for population health and health inequities, including the persistence of racial disparities in preterm birth and low birth weight.
\end{abstract}

Keywords: Adverse birth outcomes, Black women, Low birth weight, Mass incarceration, Maternal and child health, Preterm birth, Racial health disparities, Social epidemiology, social determinants

\footnotetext{
* Correspondence: Idyer3@tulane.edu

${ }^{1}$ Mary Amelia Douglas-Whited Community Women's Health Education

Center, Department of Global Community Health and Behavioral Sciences,

Tulane University School of Public Health and Tropical Medicine, 1440 Canal

St., New Orleans, LA 70112, USA

Full list of author information is available at the end of the article
}

(c) The Author(s). 2019 Open Access This article is distributed under the terms of the Creative Commons Attribution 4.0 International License (http://creativecommons.org/licenses/by/4.0/), which permits unrestricted use, distribution, and reproduction in any medium, provided you give appropriate credit to the original author(s) and the source, provide a link to the Creative Commons license, and indicate if changes were made. The Creative Commons Public Domain Dedication waiver (http://creativecommons.org/publicdomain/zero/1.0/) applies to the data made available in this article, unless otherwise stated. 


\section{Background}

Adverse birth outcomes are a persistent public health issue. Preterm and low birth weight infants experience greater incidence of morbidities and mortality in their developmental stages as well as in adulthood. According to the Infant Mortality Statistics 2013 Period Linked Death dataset, $36.1 \%$ of infant deaths in the U.S. were related to preterm birth, and preterm infants had mortality rates that were $63 \%$ higher than for full term infants [1]. A study of a nationally representative sample of children $(n=74,565)$ also estimated that preterm birth was the underlying cause of more than $50 \%$ of cerebral palsy diagnoses, $15-20 \%$ of intellectual disabilities, and $10-$ $15 \%$ of autism spectrum disorders and other learning disorders [2]. As these individuals mature, they additionally face higher systolic blood pressure given lower gestational age and lower birth weights, as well as low fasting plasma glucose when compared to individuals born at term and at a normal birth weight [3].

There are substantial and alarming racial disparities in reproductive health outcomes experienced by black women in the U.S. While the overall rate of preterm birth ( $<37$ weeks' gestation) has steadily declined with improvements in healthcare access and quality, nonHispanic black women continue to experience a 1.5 fold greater risk for preterm birth and double the risk of delivering a low birth weight infant $(<2500 \mathrm{~g})$ compared to women who are non-Hispanic white, inequities that appear to be increasing [4]. Emerging research is beginning to explore how the unique combination of social, economic, and environmental factors experienced by black women in the U.S. may contribute to the continuation of reproductive health disparities [5].

Mass incarceration is a markedly racialized experience in the U.S. and an issue of growing concern for researchers interested in identifying the root causes of population health inequities. On an individual level, incarceration has been associated with greater prevalence of HIV/AIDS, diabetes, hypertension, pulmonary disorders, and mental illness when compared to those who have not experienced incarceration [6,7]. At the aggregate level, mass incarceration disrupts the social and economic networks in a community and creates barriers to resources that are integral to achieving and maintaining population health [8]. Researcher Patricia Kelly contends that when communities endure the removal and reentry of large numbers of community residents via the carceral system, difficulties emerge in sustaining longterm relationships and linkages that are useful for solving everyday problems [9]. Because of the sensitivity of reproductive health to social and contextual determinants, communities affected by mass incarceration may also be vulnerable to adverse birth outcomes as related factors fluctuate [10].
In the U.S., jails are municipal or county-level detention facilities that are administered by local law enforcement agencies for the purposes of confining individuals who have been accused of or convicted for minor criminal offenses [11]. While state and federal prisons hold twice the number of people as jails, jails have almost 19 times the number of annual admissions and are perceived by criminal justice experts as the "front door" to mass incarceration [11]. As jail incarceration rates have continued to rise, there has been a disproportionate effect on black communities. Despite the fact that black individuals accounted for only $13 \%$ of the general U.S. population in 2014, they represented $35 \%$ of the total jail population [12]. The incarceration-related racial divide in Louisiana is significant, with incarceration rates that are nearly five times higher among blacks when compared to whites [13]. This inequity mirrors the entrenched racial gaps in adverse birth outcomes between black and white women in the state. In 2017, Louisiana preterm birth and low birth weight rates for non-Hispanic blacks were nearly twice the rates for non-Hispanic whites and were greater than the national average rates for all races combined [14].

The purpose of this analysis was to determine whether mass incarceration of black individuals in Louisiana is associated with adverse birth outcomes among black women. Recent studies have shown that indicators of structural racism - such as residential segregation and differential access to education, employment, income, and political power - share in the overall influence on racial health inequities as affected communities are denied equal access to the resources and opportunities needed to achieve health and well-being $[15,16]$. We hypothesized that mass incarceration would also be an indicator of structural racism in Louisiana and that the risk for preterm birth and low birth weight would be higher among black women in parishes (county equivalent) with higher prevalence of jail incarceration within the black community relative to black women in parishes with lower prevalence.

\section{Methods}

\section{Study population and outcome ascertainment}

This analysis includes all birth records issued to nonHispanic black women (black women, hereafter) in Louisiana in $2014(N=23,954)$, data accessed through the National Center for Health Statistics. We identified preterm births (those occurring < 37 weeks' gestation) and low birth weight births (those $<2500 \mathrm{~g}$ ) as our primary outcomes of interest. Birth records included a geographic identifier for maternal parish of residence for linkage to data on incarceration and other parish-level contextual factors. As all data were deidentified, this 
study was deemed exempt by Tulane University Institutional Review Board.

\section{Jail incarceration prevalence}

Our primary exposure of interest was the parish-level jail incarceration prevalence among black individuals (count of black individuals age 16 to 64 in jail per 1000 black non-incarcerated residents). Jail data were isolated from prison data for this analysis in order to specifically estimate parish-level effects. Data were provided by the Vera Institute of Justice based on analysis of incarceration trend data from the Bureau of Justice Statistics, the Census of Jails, and the Annual Survey of Jails [17]. Since some counties are too small to have their own jail facilities, they may rely on nearby jurisdictions for detention purposes. Incarceration rate estimates for these counties are derived based on data from multi-jurisdictional jails and the sending county's share of the combined resident population [18]. The incarceration prevalence was scaled by its interquartile range (IQR) for the purposes of estimating risk of preterm birth or low birth weight associated with an IQR increase in incarceration.

\section{Additional covariates}

Other measures included in the analysis were individuallevel covariates available on the birth record and known to be associated with adverse birth outcomes, including insurance type (Medicaid, private, and other, including self-pay), maternal age $(<20,20-24,25-29, \geq 30)$, parity (nulliparous, multiparous), and the Kotelchuck Index of Prenatal Care Adequacy based on the ratio of observed prenatal visits to the number that would be expected given dates of care initiation and delivery $(<50 \%=$ inadequate, $\quad 50-79 \%=$ intermediate, $\quad 80-109 \%=$ adequate and $110 \%$ or more $=$ adequate plus) $[19,20]$. In order to isolate the association between the parish-level black incarceration prevalence and adverse birth outcomes within the black community independent of differences in socioeconomic contextual factors between parishes, additional parish-level covariates were derived from the 2014 U.S. Census American Community Survey, including the Gini Index, which measures population income inequality ( $0-1$ scale), racial income inequality (absolute difference in white to black median household income), the 2010 U.S. Census classification of parishes by urbanicity (mostly urban, mostly rural, completely rural), and the percent of blacks with a bachelor's degree or higher.

\section{Statistical analysis}

We identified the distribution of maternal and parishlevel characteristics within the total study population and stratified by outcome status. We mapped parishlevel incidence of preterm birth, low birth weight, and jail incarceration across Louisiana in ArcGIS in order to visualize patterns and variation. Next, we fit modified Poisson regression models with generalized estimating equations to account for women clustered within parishes. The first model (Model A), estimated the relative risk (RR) and 95\% confidence interval (CI) for preterm birth associated with an IQR increase in the prevalence of incarcerated black persons, adjusted for maternal and parish-level characteristics. Model B included the same covariates with low birth weight as the outcome.

Lastly, we conducted sensitivity analyses to test the robustness of our findings. Given the growing body of literature highlighting the association between area violence and adverse reproductive health outcomes [21-23], we sought to explore the degree to which high incarceration prevalence simply reflected greater exposure to crime (and its negative health consequences) as opposed to representing a broader marker of social inequality and structural determinants of health inequities for black women. Therefore, we fit the same models described above and additionally included the parish-level index crime prevalence to estimate associations with preterm birth (Model C) and low birth weight (Model D). The index crime prevalence is the count of crimes (criminal homicide, rape, robbery, aggravated assault, burglary, motor vehicle theft, larceny-theft, and arson) per 1000 residents, as described in the 2014 Uniform Crime Reporting System Report from the Federal Bureau of Investigation [24]. All data analyses were conducted in SAS 9.4. All maps used for this study were created using ArcGIS software by Esri. (ArcGIS ${ }^{\circ}$ and ArcMap ${ }^{\text {Tux }}$ are the intellectual property of Esri and are used herein under license. Copyright $\odot$ Esri. All rights reserved).

\section{Results}

A total of 23,954 births to black women were recorded in Louisiana in 2014. These births occurred across 63 of Louisiana's 64 parishes; Cameron parish (which recorded no births to non-Hispanic black women that year) was not included in the analysis. Data on jail incarcerated populations by race were not available for Tensas and Plaquemines Parishes in 2014 and therefore births in these parishes were excluded. The final analytic sample with data on all covariates included 23,762 births in 61 parishes $(99 \%$ of the total state births). Of these births, $15.34 \%$ were preterm (ranging from 8.47 to $25.53 \%$ across parishes; Fig. 1 panel a) and $14.99 \%$ were low birth weight (ranging from 5.08 to $33.33 \%$ across parishes; Fig. 1 panel b). The proportion of preterm birth was greater among those who were over 30 years old (18.75\%), used other types of insurance (21.95\%), had adequate plus prenatal care utilization (20.90\%), were multiparous $(16.55 \%)$, and were in mostly rural areas $(16.49 \%)$ 
A
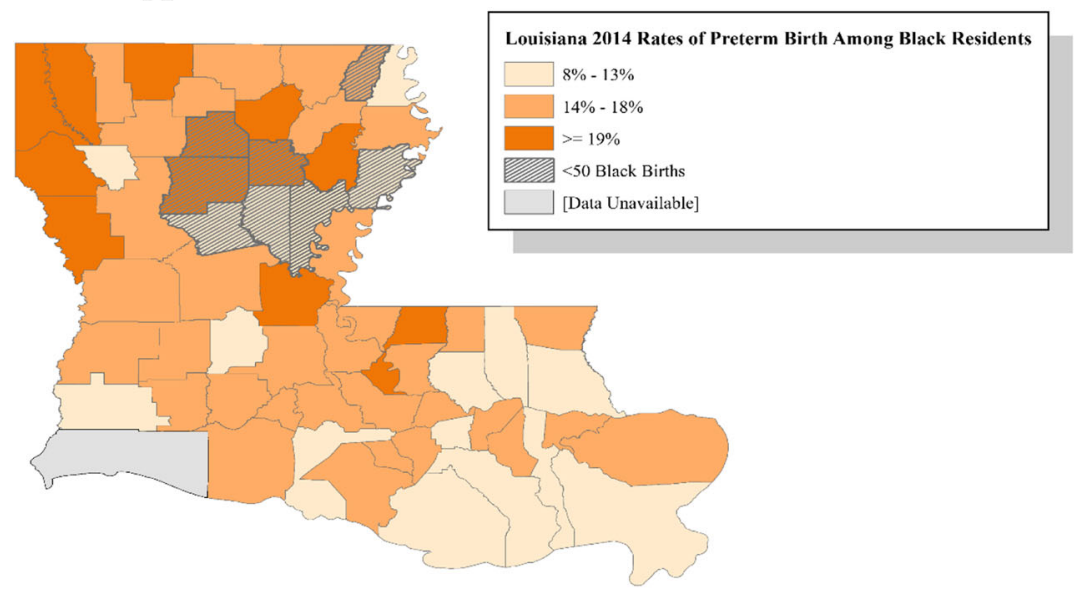

B

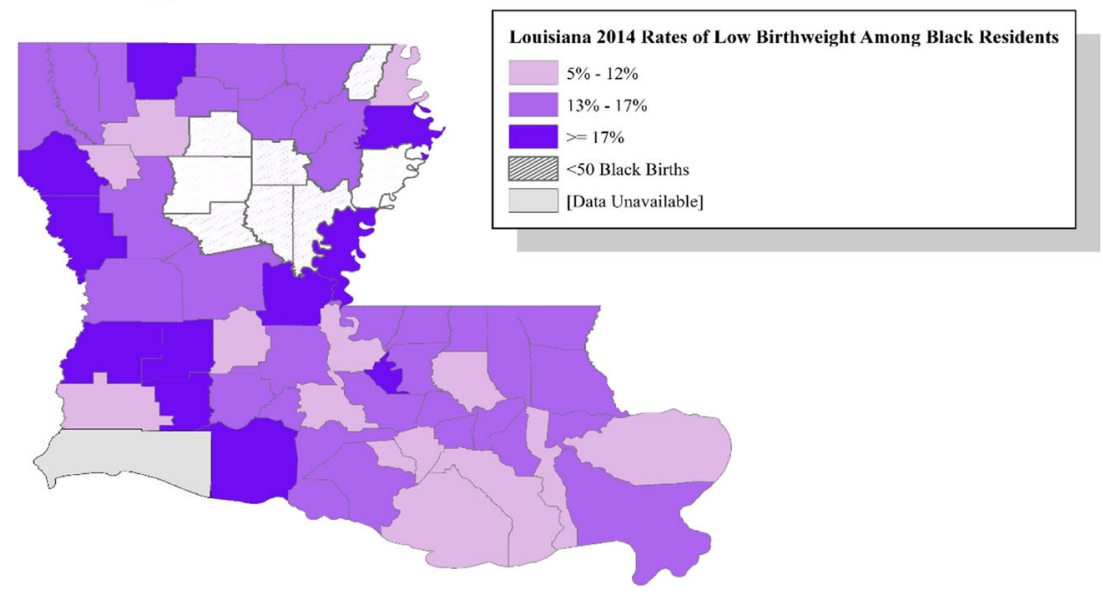

$\mathrm{C}$

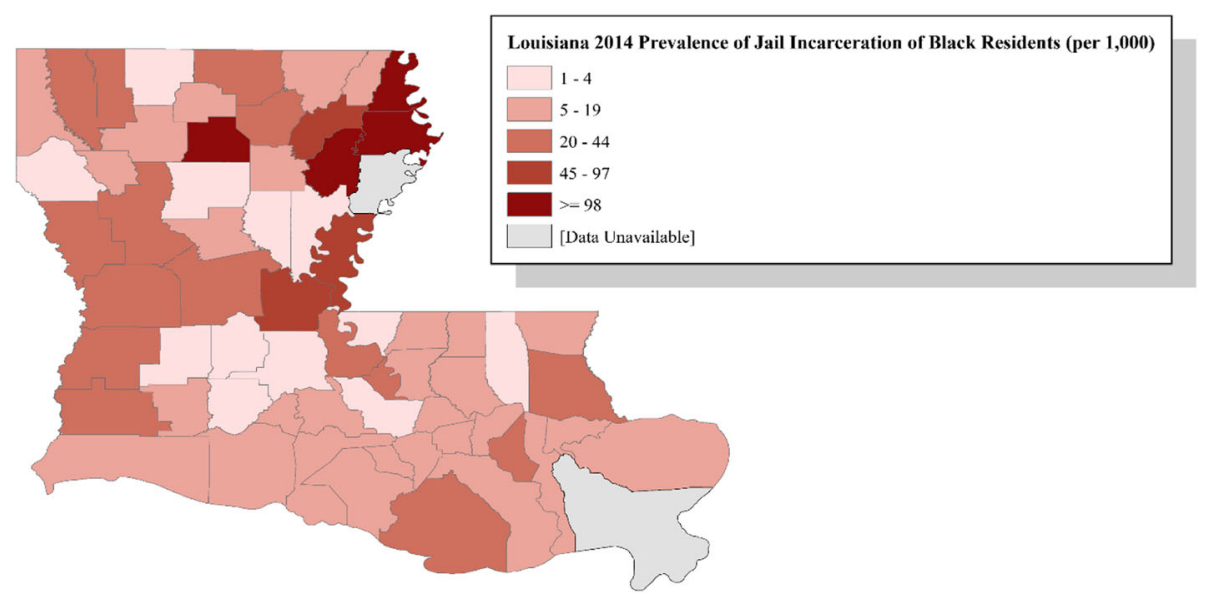

Fig. 1 Distribution of percentage of adverse birth outcomes and incarceration prevalence, by parish, Louisiana 2014

(Table 1). Among women who experienced low birth weight, prevalence was greater among women who were over 30 years old (16.80\%), used other types of insurance (19.18\%), had adequate plus prenatal care utilization (19.24\%), were multiparous (15.11\%), and were in mostly rural areas (16.22\%) (Table 1$)$. 
Table 1 Characteristics of births to non-Hispanic black women in Louisiana, 2014 ( $n=23,762)$

\begin{tabular}{|c|c|c|c|c|c|}
\hline & Total (\%) & Preterm Birth (\%) & Term Birth (\%) & Low Birth Weight (\%) & Normal Birth Weight (\%) \\
\hline & $N=23,762$ & $N=3644(15.34)$ & $N=20,118(84.66)$ & $N=3563(14.99)$ & $N=20,199(85.01)$ \\
\hline \multicolumn{6}{|l|}{ Characteristic } \\
\hline \multicolumn{6}{|l|}{ Maternal Age } \\
\hline$<20$ & $2569(10.81)$ & 344 (13.39) & $2225(86.61)$ & $398(15.49)$ & $2171(84.51)$ \\
\hline $20-24$ & 8597 (36.18) & $1188(13.82)$ & $7409(86.18)$ & $1255(14.60)$ & $7342(85.40)$ \\
\hline $25-29$ & $6767(28.48)$ & $1019(15.06)$ & $5748(84.94)$ & 931 (13.76) & $5836(86.24)$ \\
\hline $30+$ & $5829(24.53)$ & $1334(18.75)$ & $4736(81.25)$ & $979(16.80)$ & $4850(83.20)$ \\
\hline \multicolumn{6}{|l|}{ Insurance } \\
\hline Medicaid & $19,961(84.00)$ & $2974(14.90)$ & $16,987(85.10)$ & $2969(14.87)$ & $16,992(85.13)$ \\
\hline Private & $2972(12.51)$ & $488(16.42)$ & $2484(83.58)$ & 435 (14.64) & $2537(85.36)$ \\
\hline Other & $829(3.49)$ & $182(21.95)$ & $647(78.05)$ & 159 (19.18) & $670(80.82)$ \\
\hline \multicolumn{6}{|l|}{ Prenatal Care Quality ${ }^{\mathrm{a}}$} \\
\hline Inadequate & $5473(23.03)$ & $872(15.93)$ & $4601(84.07)$ & $846(15.46)$ & $4627(84.54)$ \\
\hline Intermediate & $3226(13.61)$ & 409 (12.68) & $2817(87.32)$ & $431(13.36)$ & $2795(86.64)$ \\
\hline Adequate & $6011(25.30)$ & $471(7.84)$ & $5540(92.16)$ & $544(9.05)$ & $5467(90.95)$ \\
\hline Adequate + & $9052(38.09)$ & $1892(20.90)$ & $7160(79.10)$ & $1742(19.24)$ & $7310(80.76)$ \\
\hline \multicolumn{6}{|l|}{ Parity } \\
\hline Nulliparous & 7859 (33.32) & 1019 (12.97) & $6840(87.03)$ & 1166 (14.84) & $6693(85.16)$ \\
\hline Multiparous & 15,730 (66.68) & 2604 (16.55) & $13,126(83.45)$ & 2377 (15.11) & 13,353 (84.89) \\
\hline \multicolumn{6}{|l|}{ Urbanicity } \\
\hline Mostly Urban & 20,493 (85.69) & 3105 (15.15) & $17,388(84.85)$ & $3034(14.81)$ & 17,459 (85.19) \\
\hline Mostly Rural & 2904 (12.22) & 479 (16.49) & $2425(83.51)$ & $471(16.22)$ & 2433 (83.78) \\
\hline Completely Rural & $365(1.54)$ & 60 (16.44) & 305 (83.56) & $58(15.89)$ & 307 (84.11) \\
\hline
\end{tabular}

a Kotelchuck Adequacy of Prenatal Care Utilization Index

Incarceration prevalence varied across parishes in Louisiana from .76 per 1000 residents in Acadia Parish to 169.75 per 1000 residents in Winn Parish (Fig. 1 panel c). On average across births, the maternal parish incarceration rate was 16.58 per 1000 residents. The average Gini coefficient was .49, the average percentage of blacks with a bachelor's degree or higher was $15 \%$ and the average absolute difference in median household income was $\$ 28,0009.69$ (Table 2).

Model A indicated that the relative risk for preterm birth was 3\% higher per IQR increase in the prevalence of incarcerated black individuals after controlling for individual and contextual covariates (adjusted $R R=1.03$; 95\% CI: 1.00-1.06) (Table 3). Model B yielded an estimate of similar magnitude for low birth weight. The relative risk of low birth weight per IQR increase in the jail prevalence was 1.02 (95\% CI: .99-1.05).

Results of the sensitivity analyses were consistent with our primary findings. Estimates of the association between incarceration prevalence and both preterm birth (Model C) and low birth weight (Model D) were essentially unchanged after the addition of the parish-level crime prevalence (Table 4). When additionally controlling for the index crime prevalence, women living in parishes with greater incarceration still experienced 3-4\% higher risk for preterm birth or low birth weight relative to women in parishes with less incarceration (preterm birth $\mathrm{RR}=1.04$; $95 \% \mathrm{CI}: 1.01-1.07$; low birth weight $\mathrm{RR}=$

Table 2 Characteristics of Louisiana Parishes of Residence, $2014(n=63)$

\begin{tabular}{|c|c|}
\hline & Mean (IQR) \\
\hline Black jail incarceration per 1000 residents & $16.57(21.27)$ \\
\hline Absolute difference in white/black median household income (2014 inflation-adjusted US dollars) & $28,009.69(6600.34)$ \\
\hline Gini index & $.49(.04)$ \\
\hline Black educational attainment ${ }^{a}$ & $15(.5)$ \\
\hline
\end{tabular}

\footnotetext{
a Percent of the non-Hispanic black population age 25 and older with a bachelor's or higher degree
} 
Table 3 Adjusted relative risks (RR) for preterm birth and low birth weight associated with black jail incarceration

\begin{tabular}{|c|c|c|c|c|c|}
\hline Variable & Categories & $\begin{array}{l}\text { Preterm Birth } \\
\text { Model A } \\
\text { RR }(95 \% \text { Cl) }\end{array}$ & $p$ value & $\begin{array}{l}\text { Low Birth Weight } \\
\text { Model B } \\
\text { RR }(95 \% \text { Cl) }\end{array}$ & $p$ value \\
\hline Black jail incarceration prevalence (per IQR ${ }^{\mathrm{b}}$ increase) & & $1.03(1.00-1.06)$ & .0269 & $1.02(.99-1.05)$ & .1148 \\
\hline \multirow[t]{4}{*}{ Maternal age } & $<20$ & $1.06(.92-1.21)$ & .4145 & $1.08(.95-1.22)$ & .2344 \\
\hline & $20-24$ & Reference & & & \\
\hline & $25-29$ & $1.03(.96-1.10)$ & .4537 & $.93(.83-1.04)$ & .2043 \\
\hline & $30+$ & $1.22(1.12-1.33)$ & $<.0001$ & $1.11(1.00-1.23)$ & .0471 \\
\hline \multirow[t]{3}{*}{ Insurance } & Medicaid & $.99(.91-1.08)$ & .8186 & $1.08(.98-1.19)$ & .1321 \\
\hline & Private & Reference & & & \\
\hline & Other & $1.43(1.15-1.78)$ & .0013 & $1.38(1.22-1.57)$ & $<.0001$ \\
\hline \multirow[t]{4}{*}{ Prenatal care utilization index ${ }^{c}$} & Inadequate & $1.99(1.77-2.23)$ & $<.0001$ & $1.69(1.53-1.86)$ & $<.0001$ \\
\hline & Intermediate & $1.58(1.34-1.86)$ & $<.0001$ & $1.45(1.29-1.64)$ & $<.0001$ \\
\hline & Adequate & Reference & & & \\
\hline & Adequate + & $2.65(2.40-2.91)$ & $<.0001$ & $2.14(1.95-2.35)$ & $<.0001$ \\
\hline \multirow[t]{2}{*}{ Parity } & Nulliparous & Reference & & & \\
\hline & Multiparous & $.82(.78-.87)$ & $<.0001$ & $.99(.92-1.07)$ & .8187 \\
\hline \multirow[t]{3}{*}{ Urbanicity } & Mostly Urban & Reference & & & \\
\hline & Mostly Rural & $1.11(.94-1.31)$ & .2261 & $1.14(1.01-1.29)$ & .0335 \\
\hline & Completely Rural & $1.19(.82-1.73)$ & .3684 & $1.16(.88-1.54)$ & .2945 \\
\hline White - black median household income difference & & $.99(.90-1.10)$ & .953 & $1.03(.95-1.11)$ & .5088 \\
\hline Gini index & & $.79(.16-3.89)$ & .7795 & $.59(.24-1.48)$ & .268 \\
\hline Black educational attainment $^{d}$ & & $1.45(.60-3.49)$ & .4088 & $1.70(.69-4.16)$ & .2449 \\
\hline
\end{tabular}

1.03; 95\% CI:1.00-1.05.). In a supplemental sensitivity analysis, predicting the association between white incarceration prevalence while controlling for confounders did not yield significant results with the primary outcomes (preterm birth $\mathrm{RR}=1.00$; 95\%CI: .99-1.01; low birth weight $\mathrm{RR}=.99 ; 95 \% \mathrm{CI}$. $99-1.00)$ (Table 5).

\section{Discussion}

This cross-sectional analysis of births among black women in Louisiana demonstrated that higher parishlevel incarceration prevalence for black individuals were associated with significantly greater risks for preterm birth among parish residents. These results suggest that mass incarceration may - at least in part - contribute to the racial disparity in adverse birth outcomes in Louisiana. Moreover, this association was not explained by greater prevalence of crime in areas with high incarceration, as demonstrated in the sensitivity analysis, implying that prevalence of incarcerated black persons may be an important marker of structural inequality and a determinant of adverse birth outcomes among black women. Additional sensitivity analyses also demonstrated that white incarceration prevalence was not predictive of preterm birth or low birth weight among black women, suggesting that high incarceration overall may not be a proxy for a social condition impacting both blacks and whites, and is instead an indicator of the racism experienced by blacks.

While prior research has provided evidence of associations between mass incarceration and other public health outcomes [25], few studies have investigated the association between mass incarceration and preterm birth or low birth weight among black women in particular. The results of our analysis are generally in accordance with the minimal, but growing, body of literature on mass incarceration and reproductive health equity. For example, Wildeman's analysis of Pregnancy Risk Assessment and Monitoring System linked data from 1990 to 2003 suggested that mass incarceration has a "substantial and significant" effect on black infant mortality [26]. In a separate analysis of health consequences of mass incarceration in an unbalanced panel dataset of developed democracies, including the U.S. 1981-2007 $(N=414)$, Wildeman concluded that with each 1 per 1000 increase in incarceration, there was a .25 per 1000 increase in the U.S. infant mortality rate [27]. Wildeman 
Table 4 Sensitivity analysis of violent crime in the association between birth outcomes and black jail incarceration

\begin{tabular}{|c|c|c|c|c|c|}
\hline Variable & Categories & $\begin{array}{l}\text { Preterm Birth } \\
\text { Model C } \\
\text { RR }(95 \% \text { Cl) }\end{array}$ & $p$ value & $\begin{array}{l}\text { Low Birth Weight } \\
\text { Model D } \\
\text { RR }(95 \% \text { Cl) }\end{array}$ & $p$ value \\
\hline Black Jail Incarceration Prevalence (per IQR ${ }^{b}$ increase) & & $1.04(1.01-1.07)$ & .0074 & $1.03(1.00-1.05)$ & .0440 \\
\hline \multirow[t]{4}{*}{ Maternal age } & $<20$ & $1.06(.92-1.21)$ & .4281 & $1.08(.95-1.22)$ & .2457 \\
\hline & $20-24$ & Reference & & & \\
\hline & $25-29$ & $1.03(.96-1.10)$ & .432 & $.93(.83-1.04)$ & .2087 \\
\hline & $30+$ & $1.22(1.12-1.33)$ & $<.0001$ & $1.11(1.00-1.23)$ & .0421 \\
\hline \multirow[t]{3}{*}{ Insurance } & Medicaid & $.99(.91-1.08)$ & .8537 & $1.08(.98-1.19)$ & .1249 \\
\hline & Private & Reference & & & \\
\hline & Other & $1.43(1.15-1.79)$ & .0012 & $1.38(1.22-1.57)$ & $<.0001$ \\
\hline \multirow[t]{4}{*}{ Prenatal care utilization index ${ }^{c}$} & Inadequate & $1.99(1.78-2.24)$ & $<.0001$ & $1.69(1.53-1.87)$ & $<.0001$ \\
\hline & Intermediate & $1.56(1.32-1.84)$ & $<.0001$ & $1.44(1.28-1.63)$ & $<.0001$ \\
\hline & Adequate & Reference & & & \\
\hline & Adequate + & $2.66(2.42-2.92)$ & $<.0001$ & $2.15(1.96-2.36)$ & $<.0001$ \\
\hline \multirow[t]{2}{*}{ Parity } & Nulliparous & Reference & & & \\
\hline & Multiparous & $1.21(1.15-1.27)$ & $<.0001$ & $1.01(.93-1.09)$ & .8754 \\
\hline \multirow[t]{3}{*}{ Urbanicity } & Mostly Urban & Reference & & & \\
\hline & Mostly Rural & $1.18(.99-1.39)$ & .0563 & $1.20(1.06-1.36)$ & .0042 \\
\hline & Completely Rural & $1.35(.92-1.99)$ & .1284 & $1.29(.97-1.72)$ & .0828 \\
\hline White - black median household income difference per 10,000 & & $1.01(.91-1.11)$ & .8853 & $1.05(.97-1.13)$ & .2148 \\
\hline Gini & & $.34(.05-2.19)$ & .2652 & $.31(.11-.88)$ & .0277 \\
\hline Black educational Attainment $^{d}$ & & $1.52(.64-3.59)$ & .3385 & $1.77(.79-3.97)$ & .1667 \\
\hline Crime Rate (per IQR increase) & & $1.00(1.00-1.01)$ & .0311 & $1.04(.96-1.12)$ & .3711 \\
\hline
\end{tabular}

also found that for each 1 per 1000 increase in U.S. incarceration, there is an associated .29 (for U.S. males) and .37 (for U.S. females) decline in life expectancy years at birth for the sample, with these associations being highly significant at the .001 level. The present study and others suggest that mass incarceration may have long-term implications for population and perinatal health outcomes.

Chronic and psychosocial stress is another important risk factor for adverse birth outcomes, as demonstrated by a study in which preconception stress increased the odds for preterm birth by $19 \%$ and the odds of smallfor-gestational-age birth by $14 \%$, and consequentially increased the odds of infant mortality [28]. Mass incarceration is hypothesized to produce uniquely stressful situations because normal family functioning is disrupted and social and financial difficulties arise when helping formerly incarcerated relatives readjust to society [25]. For black women living in communities affected by mass incarceration, the increased exposure to these new stressors can lead to adverse birth outcomes. In a study of 5470 adults in the National Survey of American
Life, Lee et al. estimated that women with an incarcerated family member experienced 1.44 times the odds of heart attack, stroke, diabetes, and obesity [29]. Lee et al. also postulate that women affected by incarceration are often already experiencing multiple stressors - such as poverty and community violence - even before this additional hardship. Another study found that women who lived in neighborhoods with greater levels of physical and social disorder - as well as violent crime - demonstrated increased levels of psychological distress and a higher risk for preterm birth [30]. The relationship between high incarceration prevalence and adverse birth outcomes may thus also be explained as a reaction to the stress experienced by pregnant individuals living in areas affected by mass incarceration.

With the increasing need for comprehensive interventions on the persistent gaps in perinatal outcomes for black women in the U.S., attention must be paid to factors that systematically disadvantage black communities, such as discriminatory arrest practices, unfair sentencing laws, and overuse of the bail system. For example, little is known about how disproportionally high contact with 
Table 5 Sensitivity analysis of preterm birth and low birth weight risk associated with white jail incarceration

\begin{tabular}{|c|c|c|c|c|c|}
\hline Variable & Categories & $\begin{array}{l}\text { Preterm Birth } \\
\text { Model E } \\
\text { RR }(95 \% \mathrm{Cl})^{\mathrm{a}}\end{array}$ & $p$ value & $\begin{array}{l}\text { Low Birth Weight } \\
\text { Model F } \\
\text { RR }(95 \% \text { Cl) }\end{array}$ & $p$ value \\
\hline White Jail Incarceration Prevalence (per IQR increase) & & $1.00(.99-1.01)$ & .8758 & $.99(.99-.1 .00)$ & .8564 \\
\hline \multirow[t]{4}{*}{ Maternal age } & $<20$ & $1.06(.93-1.21)$ & .4084 & $1.08(.95-1.22)$ & .2307 \\
\hline & $20-24$ & Reference & & & \\
\hline & $25-29$ & $1.03(.96-1.10)$ & .447 & $.93(.83-1.04)$ & .2065 \\
\hline & $30+$ & $1.22(1.12-1.33)$ & $<.0001$ & $1.11(1.00-1.23)$ & .0484 \\
\hline \multirow[t]{3}{*}{ Insurance } & Medicaid & $.99(.91-1.08)$ & .816 & $1.08(.98-1.19)$ & .1326 \\
\hline & Private & Reference & & & \\
\hline & Other & $1.44(1.16-1.78)$ & .001 & $1.38(1.22-1.57)$ & $<.0001$ \\
\hline \multirow[t]{4}{*}{ Prenatal care utilization index ${ }^{b}$} & Inadequate & $1.99(1.77-2.23)$ & $<.0001$ & $1.69(1.53-1.86)$ & $<.0001$ \\
\hline & Intermediate & $1.59(1.35-1.87)$ & $<.0001$ & $1.46(1.29-1.65)$ & $<.0001$ \\
\hline & Adequate & Reference & & & \\
\hline & Adequate + & $2.64(2.39-2.91)$ & $<.0001$ & $2.14(1.94-2.35)$ & $<.0001$ \\
\hline \multirow[t]{2}{*}{ Parity } & Nulliparous & Reference & & & \\
\hline & Multiparous & $.82(.78-.87)$ & $<.0001$ & $.99(.92-1.07)$ & .8032 \\
\hline \multirow[t]{3}{*}{ Urbanicity } & Mostly Urban & Reference & & & \\
\hline & Mostly Rural & $1.12(.94-1.33)$ & .2028 & $1.15(1.01-1.31)$ & .03 \\
\hline & Completely Rural & $1.17(.79-1.70)$ & .4298 & $1.15(.86-1.52)$ & .3467 \\
\hline White - black median household income difference per 10,000 & & $.99(.89-1.09)$ & .8665 & $1.02(.94-1.11)$ & .605 \\
\hline Gini & & $.79(.16-3.93)$ & .7782 & $.60(.24-1.51)$ & .279 \\
\hline Black educational Attainment ${ }^{c}$ & & $1.23(.49-3.03)$ & .6526 & $1.49(.59-3.79)$ & .3914 \\
\hline
\end{tabular}

a $95 \%$ Confidence Interval

${ }^{\mathrm{b}}$ Kotelchuck Adequacy of Prenatal Care Utilization Index

c Percent of the non-Hispanic black population age 25 and older with a bachelor's or higher degree

the criminal justice system among black individuals impacts population health and well-being. However, the findings of this study suggest that such a connection exists and that there are specific effects on black perinatal health. Inequities may also persist because race and gender are closely tied to resources like money, power, prestige, and social connectedness, and access to them is so integral to avoiding and minimizing disease that they should be considered potential fundamental causes of disease as well [31]. Tyan Parker Dominguez suggests that public health researchers and practitioners must shift focus from individual level risk factors to larger social forces that affect disease risk - including mass incarceration [32]. Dominguez also emphasizes that racism is a major contributor to health disparities since health outcomes are strongly influenced by socially constructed notions of race. In addition, there is growing interest in the use of the "life-course" approach to public health interventions to effectively eliminate reproductive health disparities by addressing early life disadvantages and lifelong exposure to social determinants such as neighborhood poverty, crime, segregation, and racism [33].

This study has several limitations. Firstly, the crosssectional nature of the data does not allow for conclusions to be drawn about causal pathways in the association between mass incarceration and adverse birth outcomes. Complete data on incarceration trends in Louisiana were only available up to 2014, so we were unable to analyze data that have become available following the 2017 adoption of comprehensive criminal justice reform in Louisiana which has resulted in a $2.9 \%$ decrease in state prison admissions of any type, and a $7.6 \%$ decrease in the total prison population [34]. Similarly, the data for birth outcomes- as well as for certain covariates, such as insurance type and prenatal care utilization - may have been affected by the expansion of Medicaid in Louisiana in 2016. As this reform was integral to changing the healthcare landscape of Louisiana, and since these covariates had strong effects on the preterm birth and low birth weight models, post-expansion data on these confounders should be analyzed as well. Future longitudinal research could explore how the association has changed over time and how criminal justice and healthcare reforms have impacted reproductive health equity in Louisiana. Additionally, while we controlled for several individual- and parish-level characteristics known to be associated with health 
outcomes, we acknowledge the possibility of residual confounders that may differ between women or parishes and contribute to preterm birth or low birth weight risk (racial residential segregation or other markers of structural racism such as racial inequality in employment and educational attainment, for example). There may be concerns about underreporting of crime in the FBI's Uniform Crime Reporting System (the data source utilized for our measure of county-level crime prevalence), yielding a conservative estimate of both the true incidence and our measures of its association with adverse birth outcomes. Birth outcome incidence estimates for parishes with fewer than 50 black births should be interpreted with caution due to the small sample size. Lastly, since this analysis was conducted with black women in Louisiana the results may not be generalizable to other populations or women in other states.

\section{Conclusions}

While scant research considers the indirect health consequences of mass incarceration, there is growing acceptance that it is a critical determinant of public health. Our findings support the notion that mass incarceration is a "social-structural" determinant of public health outcomes. Furthermore, given the disproportionate number of black people incarcerated in the U.S., mass incarceration is a critical indicator of structural inequity and must be acknowledged as a way that structural racism causes fundamental health inequity in our society [35], making Louisiana an important case study for understanding complex questions related to mass incarceration and reproductive health. To reduce the persistent inequities in adverse birth outcomes experienced by black women in the U.S., more research should focus on structural factors that contribute to poor health. Through collaborative research, mass incarceration can be viewed through a public health lens and partnerships between public health institutions and criminal justice officials can be utilized for monitoring incarceration data trends and formulating evidence-based interventions for improving the quality of life of those affected by mass incarceration and to reduce its overall social impact. Additionally, justice reforms can result in more fair and equitable sentencing practices, as has been seen in states who have adopted legislation to reduce sentences for minor offenses. In Louisiana, for example, recent bipartisan legislative support ended nonunanimous jury verdicts in felony trials in New Orleans, a decision expected to reduce unwarranted lengthy sentences and reduce racial bias in certain convictions [36]. Our findings compel the replication of these analyses in other states and counties with available data so that results may be compared and a more comprehensive understanding of the relationship between mass incarceration and birth outcome disparities among the black population can emerge. In particular, high prevalence of both incarceration and adverse birth outcomes across southern US states suggest the relevance of our hypothesis to their contexts as well.

\section{Abbreviations \\ Cl: Confidence Interval; IQR: Interquartile range; RR: Relative Risk}

\section{Acknowledgements}

Not applicable.

\section{Authors' contributions}

LD conceived the study. LD and MW conducted and interpreted the analysis. $\mathrm{RH}, \mathrm{DV}$, and $\mathrm{KT}$ interpreted the analysis and were major contributors in writing the manuscript. All authors read, contributed to, and agreed to the final version of the manuscript prior to submission.

\section{Funding}

This work was supported by funds from the National Institute of Child Health and Human Development, National Institutes of Health (R01HD092653). [AUTHOR's] role in this research was supported by the National Heart Lung and Blood Institute, National Institutes of Health under award numbers R01HL085631, R01HL085631-S2, R01HL085631-S3 and by the Robert Wood Johnson Foundation Interdisciplinary Research Leaders program. The institutions responsible for providing funding for this study had no involvement in designing the study, collecting, interpreting, or analyzing data, or writing the manuscript.

\section{Availability of data and materials}

The data that support the findings of this study are available from the National Center for Health Statistics, but restrictions apply to the availability of these data, which were used under license for the current study, and so are not publicly available. Data are however available from the authors upon reasonable request and with permission of the National Center for Health Statistics.

\section{Ethics approval and consent to participate}

As all data were deidentified, this study was deemed exempt from ethics approval by Tulane University's Institutional Review Board. No administrative permissions or licenses were acquired for the purposes of this study.

Consent for publication

Not applicable.

\section{Competing interests}

The authors declare that they have no competing interests.

\section{Author details}

${ }^{1}$ Mary Amelia Douglas-Whited Community Women's Health Education Center, Department of Global Community Health and Behavioral Sciences, Tulane University School of Public Health and Tropical Medicine, 1440 Canal St., New Orleans, LA 70112, USA. ²Division of Health Policy and Management, University of Minnesota School of Public Health, 420 Delaware St SE, Minneapolis, MN 55455, USA.

Received: 11 June 2019 Accepted: 19 December 2019

Published online: 27 December 2019

\section{References}

1. Mathews TJ MM, Thomas ME. Infant Mortality Statistics from the 2013 Period Linked Birth/Infant Death Data Set. 2015. Contract No.: 9.

2. Schieve LA, Tian LH, Rankin K, Rogan MD, Allsopp MY, Visser S, Rosenberg D. Population impact of preterm birth and low birth weight on developmental disabilities in US children. Ann Epidemiol. 2016;26(4):267-74. 
3. Irving RBN, Elton RA, Walker BR. Adult cardiovascular risk factors in premature babies. Lancet. 2000;355:2135-6.

4. Hamilton BE, Martin JA, Osterman MJ, Rossen LM. Births: provisional data for 2018. National Vital Statistics System; 2019.

5. Burris $H$, Hacker MR. Birth outcome racial disparities: a result of intersecting social and environmental factors. Semin Perinatol. 2017:41(6):360-6.

6. Baillargeon J, Pulvino JS, Leonardson JE, Linthicum LC, Williams B, Penn J, et al. The changing epidemiology of HIV in the criminal justice system. Int J STD AIDS. 2017;28(13):1335-40.

7. Vail WL, Niyogi A, Henderson N, Wennerstrom A. Bringing it all back home: understanding the medical difficulties encountered by newly released prisoners in New Orleans, Louisiana - a qualitative study. Health Soc Care Community. 2017;25(4):1448-58.

8. Schnittker J, Uggen C, Shannon SKS, Mcelrath SM. The Institutional Effects of Incarceration: Spillovers From Criminal Justice to Health Care. Milbank Q. 2015;93(3):516-60

9. Kelly PJ. Mass incarceration. Public Health Nurs. 2015;32(1):1-2.

10. Culhane JF, Elo IT. Neighborhood context and reproductive health. Am J Obstet Gynecol. 2005;192:S22-9.

11. Subramanian R, Delaney R, Roberts S, Fishman N, McGarry P. Incarceration's front door: the misuse of jails in America. New York: Vera Institute of Justice; 2015

12. Subramanian R, Henrichson C, Kang-Brown J. In our own backyard: confronting growth and disparities in American jails. New York: Vera Institute of Justice; 2015

13. Mauer M, King RS. Uneven Justice: State Rates of Incarceration by Race and Ethnicity. Washington, D.C.: The Sentencing Project; 2007.

14. State Health Facts [Internet]. San Francisco: Henry J Kaiser Family Foundation. Health Status Indicators: Births. Available from: https://www.kff. org/state-category/health-status/births/.

15. Williams DR, Lawrence JA, Davis BA. Racism and Health: Evidence and Needed Research. Ann Rev Public Health. 2018:40:14.1-21.

16. Bailey ZD, Krieger N, Agenor M, Graves J, Linos N, Bassett MT. Structural racism and health inequities in the USA: evidence and interventions. Lancet. 2017;389(10077):8-14.

17. Incarceration Trends Dataset [Internet]. New York: Vera Institute of Justice; 2015. Available from http://trends.vera.org/incarceration-rates. 2015.

18. Kang-Brown J, Hinds O. Incarceration Trends Project: Data and Methods for Historical Jail Populations in U.S. Counties, 1970-2015. New York: Vera Institute of Justice; 2018

19. Kotelchuck M. An evaluation of the Kessner adequacy of prenatal care index and a proposed adequacy of prenatal care utilization index. Am J Public Health. 1994:84(9):1414-20.

20. Gwin KM, Schrader R, Peters K, Moreno A, Thiel KW, Leslie KK. An exploratory study of the variables impacting preterm birth rates in New Mexico. BMC Pregnancy Childbirth. 2012;12(53):1-8.

21. Messer LC, Kauffman JS, Dole N, Herring A, Laraia BA. Neighborhood crime, deprivation, and preterm birth. Ann Epidemiol. 2006;16:455-62.

22. Felker-Kantor $\mathrm{E}$, Wallace $\mathrm{M}$, Theall $\mathrm{K}$. Living in violence: neighborhood domestic violence and small for gestational age births. Health Place. 2017:46:130-6.

23. Messina LC, Kramer MR. Multilevel analysis of small area violent crime and preterm birth in a racially diverse urban area. Int J Disabil Hum Dev. 2013; 2(4):445.

24. U.S. Dept. of Justice, Federal Bureau of Investigation [Internet]. Washington, D.C.: Uniform Crime Reporting Program. UCR Offense Definitions 2017. Available from: https://www.ucrdatatool.gov/offenses.cfm.

25. Wildeman C, Wang EA. Mass incarceration, public health, and widening inequality in the USA. Lancet. 2017;389:1464-74.

26. Wildeman C. Imprisonment and infant mortality. Soc Probl. 2012;59(2): 228-57.

27. Wildeman C. Incarceration and population health in wealthy democracies. Criminology. 2016;52(2):360-82

28. Class QA, Khashan AS, Lichtenstein P, Langstrom N, D'onofrio BM. Maternal stress and infant mortality: the importance of the preconception period. Psychol Sci. 2013;24(7):1309-16.

29. Lee $H$, Wildeman C, Wang EA, Matusko N, Jackson JS. A heavy burden: the cardiovascular health consequences of having a family member incarcerated. Res Pract. 2014;104(3):421-7.

30. Giurgescu C, Zenk SN, Templin TN, Engeland CG, Kavanaugh K, Misra DP. The impact of neighborhood conditions and psychological distress on preterm birth in African American women. Public Health Nurs. 2017; 34(3):256-66.

31. Link BG, Phelan J. Social Conditions As Fundamental Causes of Disease. J Health Soc Behav. 1995:(35):80-94.

32. Dominguez TP. Adverse birth outcomes in African American women: the social context of persistent reproductive disadvantage. Soc Work Public Health. 2011:26(1):3-16.

33. Matoba N, Collins JW Jr. Racial disparity in infant mortality. Semin Perinatol. 2017:41:354-9

34. Louisiana Department of Public Safety \& Corrections Louisiana Commission on Law Enforcement (US). Louisiana's Justice Reinvestment Reforms First Annual Performance Report. Baton Rouge: State of Louisiana; 2018. 56 p.

35. Phelan J, Link BG. Is racism a fundamental cause of inequalities in health? Ann Review Sociol. 2015;41:311-30.

36. Indivisible [Internet]. Washington, D.C.: The Indivisible Project; 2019. Louisiana Amendment 2: Unanimous Jury Decisions. Available from: https:// indivisible.org/resource/louisiana-amendment-2-unanimous-jury-decisions.

\section{Publisher's Note}

Springer Nature remains neutral with regard to jurisdictional claims in published maps and institutional affiliations.
Ready to submit your research? Choose BMC and benefit from:

- fast, convenient online submission

- thorough peer review by experienced researchers in your field

- rapid publication on acceptance

- support for research data, including large and complex data types

- gold Open Access which fosters wider collaboration and increased citations

- maximum visibility for your research: over $100 \mathrm{M}$ website views per year

At $\mathrm{BMC}$, research is always in progress.

Learn more biomedcentral.com/submissions 